\title{
Umbrella Advocates Versus Validity Police: A Life-Cycle Model
}

\author{
Paul M. Hirsch • Daniel Z. Levin \\ Department of Organization Behavior, J. L. Kellogg Graduate School of Management, Northwestern University, \\ Evanston, Illinois 60208 \\ Organization Management Department, Faculty of Management, Rutgers University, \\ Newark, New Jersey 07102-1820
}

\begin{abstract}
Some who study organizations see broad patterns; others see a myriad of more narrowly defined $N_{\text {problems and issues. This article portrays organization science as a dialectic wherein the former }}$ scholars synthesize regularities into integrative "umbrella constructs," which the latter challenge as too broad and inconsistent, playing the role of "validity police." Tensions between rigor and relevance, and paradigms and pluralism are framed as byproducts of a life cycle of scholarly constructs.
\end{abstract}

Alan D. Meyer

\begin{abstract}
The rise and fall of organizational effectiveness, an "umbrella construct" once at the forefront of organizational theory, is traced through four life-cycle stages: emerging excitement, the validity challenge, "tidying up with typologies," and construct collapse. Although the study of effectiveness has declined, research on its component elements continues to thrive. Using the effectiveness story as an exemplar, we develop a more general model of this process for all umbrella constructs, defined here as broad concepts used to encompass and account for a diverse set of phenomena. This life-cycle model-driven largely by a dialectic between researchers with a broad perspective ("umbrella advocates") and those with a narrower one ("validity police")-leaves open the possibility that some umbrella constructs may ultimately be made coherent or remain permanently controversial rather than collapse, as effectiveness has done. We propose that umbrella constructs will arise most frequently in academic fields without a theoretical consensus, will inevitably have their validity seriously challenged, will have a shorter life than their constituent elements, and will be more vulnerable to validity challenges when they lack support from practitioners. This model's implications for the future direction of such current umbrella constructs as organizational learning, culture, strategy, and performance are also explored and elaborated. Ironically, some evidence suggests that studies around the construct of organizational "performance" have arisen to replace the nearly identical, but fallen umbrella construct of organizational effectiveness.

(Sociology of Organization Science; Paradigms; Theory Development; Organization Theory; Umbrella Constructs)
\end{abstract}

The question for organizational science is whether the field can strike an appropriate balance between theoretical tyranny and an anything-goes attitude. (Pfeffer 1993, p. 616)

Organizational science is characterized by its attention to successive concepts, with different (but often related) terminologies, that conform to a life-cycle of: emerging excitement, followed by critique, and either transformation or decline. While some maintain that the resulting field is little more than theoretical labeling and relabeling, that organizational behavior is a language game (Astley 1985), we argue that these "labels" follow regular, nonrandom, and nontrivial patterns based on a dialectic that ultimately strengthens the field, even though this may appear highly disruptive at times. To bring order to this variety and multiplicity of frameworks, the field could select a single perspective to organize around (Pfeffer 1993). That approach attempts to transcend the standard life cycles of theoretical formulations, documented by sociologists of science (Mullins 1973, Zuckerman 1988, Abrahamson 1999). While a single framework could bring the field more in line with its self-image as a linear and cumulative science, we propose that a more evolutionary life-cycle pattern of concepts, encompassing their birth, maturity, and decline, provides a scholarly 
dynamic, or dialectic, that is both descriptively accurate and intellectually valuable.

This dynamic, which sets our life-cycle model in motion, takes place between two forces within the field. On one side are those who argue that broad (umbrella) perspectives are necessary to keep the field relevant and in touch with the larger, albeit messier, world. We call this first group umbrella advocates and believe that without them our field risks becoming disconnected and irrelevant. On the other side are more methodologically oriented researchers who call for narrower perspectives that conform to more rigorous standards of validity and reliability. We call this second group the validity police, and without them, we argue, our field risks becoming too sloppy and scattered. Note that this debate over the fate of umbrella constructs-the topic of this paper-is in many ways analogous to other ongoing battles within the field of organizational behavior: between, for example, processual and structural (Meyer 1991), interpretive and functionalist (Barley et al. 1988), the tension between external and internal validity (Cook and Campbell 1979), exploration versus exploitation (March 1996), and between relevance and rigor. Rather than argue the merits of only one side, however, we believe the field needs the two types of problem framing to remain both relevant and scientific. That is, this dialectic, between "an anything goes attitude" and "theoretical tyranny" (Pfeffer 1993, p. 616) is a useful—even necessary-part of our field, where each side's contribution includes preventing the other from going too far for too long. It facilitates what March (1996, p. 278) calls the "rough balance between openness and discipline."

Moreover, this dynamic between umbrella advocates and validity police plays out in a number of predictable and interesting ways, particularly in the case of the umbrella construct. We define an umbrella construct as a broad concept or idea used loosely to encompass and account for a set of diverse phenomena. Umbrella constructs used in organizational behavior include organizational effectiveness, learning, performance, strategy, and culture. As we shall see, consensus on how to operationalize an umbrella construct is rarely achieved. After documenting the rise and fall of organizational effectiveness as an exemplar, we will derive a more general model of the life-cycle of umbrella constructs and offer several propositions about their fate. Finally, we elaborate on the implications of this model for the future of several current umbrella constructs in organizational behavior.

\section{The Case of Organizational Effectiveness: An Exemplar}

Agreeing that the meaning of organizational effectiveness is hard to pin down and difficult to measure does not diminish in any way its central place in macro organizational behavior.... (Miles 1980, p. 359)

The construct of organizational effectiveness is the ultimate dependent variable in organizational research. (Cameron and Whetten 1983, p. 2)

Whatever happened to organizational effectiveness? At first glance, the study of this construct-at the cutting edge of organizational theory in the late 1960s, 1970s, and early 1980s - seems to have largely disappeared from the organizational behavior literature. But has it really disappeared? The question of what happened to organizational effectiveness reveals a curious puzzle: a construct that faded away yet remains alive and well. This section develops the organizational effectiveness puzzle, explaining how a construct could practically disappear from the literature while researchers continued to publish articles on the elements of that construct.

\section{The Emerging Excitement}

When the study of organizational effectiveness burst on the scene in the 1960s, effectiveness was an exciting construct at the forefront of the field of organizational behavior. In fact, the concept of effectiveness, which has long been a part of the modern study of organizations, had already become "a classic problem" in the study of organizations by the late 1960s (Price 1968, p. 3). For example, Price's (1968) inventory of propositions on organizational effectiveness drew on 50 in-depth studies of organizational effectiveness published since World War II. So important to the field was the study of organizational effectiveness that the contributing authors to the Goodman and Pennings (1977) volume on the topic included many of the leading organizational theorists of the day: Cummings, Freeman, Hannan, Kahn, Perrow, Pfeffer, Pondy, Scott, Seashore, and Weick. During this period Ghorpade $(1971$, p. 1) observed that the "current popularity of organizational effectiveness among social scientists [results in part from] the central nature of this topic to the field of organization theory." Indeed, Goodman and Pennings (1977a, p. 2) wrote that "it is difficult to conceive of a theory of organizations that does not include the construct of effectiveness." This sense of excitement about organizational effectiveness was still conveyed in the early 1980s by Cameron and Whetten (1983, p. 1), who, looking back on two decades of several hundred articles and book chapters on the topic, stated, "Theoretically, the construct of organizational effectiveness lies at the very center of all organizational models."

Much of the early excitement surrounding organizational effectiveness mirrored the ferment going on within organizational theory. In particular, the debate between a 
rational model and natural system model of organizations (Gouldner 1959) was the backdrop for two underlying approaches to studying organizational effectiveness (Kahn 1977). The rational model, emphasizing the idea that organizations are instruments for achieving goals, was exemplified by Price's (1968) definition of effectiveness as the degree of goal achievement. An alternative, rival approach, however, saw organizational effectiveness as going beyond the boundaries of rational organizations. One variation on this approach that became popular by the late 1960s was the open systems model (Katz and Kahn 1966, Thompson 1967), which saw organizations as highly interdependent with their environments. To these theorists, organizational effectiveness became defined more broadly as satisfying or responding to the constraints imposed by outsiders, and not just achieving internal goals (Katz and Kahn 1966, Goodman and Pennings 1977b, Pfeffer 1982).

In addition to this ongoing theoretical discussion of organizational effectiveness, empirical work on the subject also grew. By the late-1970s, Campbell (1977, p. 36) was able to review the organizational effectiveness literature and compile a list of 30 "variables that have been proposed seriously as indices of organizational effectiveness." Determining how all these organizational effectiveness variables fit together into an overall (umbrella) construct was a daunting task, but it was still a question open to research.

During this heyday of organizational effectiveness there were, of course, some murmurings of discontent concerning the construct's definition and validity. Katz and Kahn (1966, p. 150), for example, observed that "organizational effectiveness has become one of those handy but treacherous pseudo concepts, connoting a sort of totality of organizational goodness - a sum of such elements as productivity, cost, performance, turnover, quality of output and the like." Yuchtman and Seashore (1967) systematically critiqued the then-prevailing conceptions of organizational effectiveness. Nevertheless, Katz and Kahn (1966) and even Yuchtman and Seashore (1967) still embraced the search for new theoretical insight in this area and put forth their own definitions of and ideas about the subject. Ghorpade (1971, p. 1-2), though an advocate in his introduction to an anthology on organizational effectiveness, noted certain problems:

\footnotetext{
The recent spurt of writings and research pertaining to organizational effectiveness has not as yet resulted in the formulation of a universally acceptable scheme or methodology for the assessment of effectiveness of organizations. In fact, the concept of organizational effectiveness is surrounded by a great deal of controversy and debate. Organization theorists have advocated a perplexing variety of conceptual schemes, analytical points of
}

departure, and models for approaching the study of effectiveness. Furthermore, the literature abounds with discussions about a multitude of criteria of effectiveness.

Umbrella advocates like Ghorpade (1971, p. 2), however, remained upbeat about the prospects for overcoming the validity problems of the construct. Far from giving up on effectiveness, he continued, "The purpose of this book is to contribute towards the clarification and resolution of the basic issues involved in the study of organizational effectiveness. Such an attempt at this stage should provide a valuable starting point for the codification and synthesis of recent research and writings dealing with this highly important and timely topic."

During this "excitement" stage, organizational theorists were certainly aware that the construct had potential validity problems, but these problems were still seen less as a threat than as an exciting new opportunity for further study.

\section{The Validity Challenge}

By the mid-1970s, however, researchers began to question more seriously the validity of the organizational effectiveness construct. While organizational effectiveness may have seemed coherent intuitively, it proved impossible for theorists to agree on how to define or operationalize the construct (Shenhav et al. 1994). Advocating a "population ecology" approach, Hannan and Freeman (1977) argued that all the effectiveness criteria were inappropriate for comparative studies, and that the only valid criterion for organizational success was survival. However, the problem with looking only at survival rates, Katz and Kahn (1978) replied, is that organizational "death" can be too rare, that effectiveness is a variable for which researchers and practitioners want leading indicators and measures for relative success, as well as warning signals before an organization fails.

The various indicators of organizational effectiveness developed during its heyday, however, rarely overlapped, and so no consensus ever emerged on what exactly constituted organizational effectiveness. For example, Campbell et al. (1974) found that studies using a single organizational effectiveness variable used 19 completely different measures. Cameron (1978) compared the organizational effectiveness criteria used in 21 empirical studies and discovered that $80 \%$ of the criteria selected in those studies did not overlap. Katz and Kahn (1978) further noted that the different organizational effectiveness criteria not only did not overlap conceptually but often did not correlate empirically as well.

The first implication of the low correlation among organizational effectiveness measures was that integrated effectiveness studies became empirically difficult. If the 
many measures of effectiveness were not correlated, then they could not be reduced to just a few key common factors of effectiveness. As a result, so many different variables were needed to try to measure overall organizational effectiveness that it became practically impossible for a researcher to be comprehensive. Even worse, most researchers used whatever data on organizational effectiveness were convenient and available (Cameron and Whetten 1983), so truly comprehensive studies of effectiveness were even rarer. In fact, most of the effectiveness research had become a collection of "ad hoc, atheoretical and non-cumulative empirical studies" (Goodman et al. Schoorman 1983, p. 164), with effectiveness defined and measured by a particular outcome variable but not by any overarching construct of organizational effectiveness.

The second implication of the small overlap among organizational effectiveness indicators was that efforts to understand what exactly defined organizational effectiveness had become theoretically messy. The primary expression of this theoretical confusion was "the variety of theoretical perspectives or models that researchers have used to guide their investigations" (Scott 1977, p. 73). "Whereas some authors have vigorously championed their own conceptualization as the most appropriate one, there is no evidence to suggest that one way of looking at organizations is any better than another" (Cameron and Whetten 1983, p. 4). Nor did researchers expect to resolve this issue, because organizational behavior as a whole had not reached any consensus on a single model or theory of organizations (Goodman et al. 1983). Furthermore, many researchers concluded that a consensus could never be reached (Kanter and Brinkerhoff 1981). The "criteria for evaluating organizational effectiveness cannot be produced by some objective, apolitical process. They are always normative and often controversial" (Scott 1977, p. 89). This realization is analogous to the conclusion of some in political science that no objective and nonpartisan criteria exist for determining the "fairness" of a redistricting plan (Levin 1988). The result for organizational effectiveness research has been an accumulation of different theoretical perspectives on how to define effectiveness.

\section{Tidying Up with Typologies}

Lacking any consensus for what the effectiveness construct meant, some researchers tried to categorize the organizational effectiveness work that had already been done. Perhaps the most notable contribution along these lines was Scott's $(1977,1992)$ grouping of all the theoretical perspectives on organizational effectiveness into three broad categories: rational, natural, and open systems. The rational system model emphasized such elements of effectiveness as quality, productivity, and efficiency. The natural system model, which sees organizations as both trying to achieve their goals and maintaining themselves as social units, emphasized effectiveness criteria like morale and survival. The open system model, which views organizations as highly interdependent with their environments, focused on such organizational effectiveness elements as utilization of the outside environment, information management, and adaptability.

Quinn and Rohrbaugh (1983), in their "competing values" model, took this systematic categorization of theoretical perspectives a step further by sending out surveys to researchers who had published in Administrative Science Quarterly during a two-year period. They also took Campbell's (1977) compilation of 30 organizational effectiveness variables and definitions and asked a panel of seven organizational effectiveness researchers "to reduce the list of effectiveness criteria to contain only singular constructs pertaining to performance evaluations of organizational units. Elimination of a criterion required agreement in the judgments of at least six or seven panel members" (Quinn and Rohrbaugh 1983, p. 366), and the result was that 13 criteria were eliminated. Using the 17 elements of organizational effectiveness identified by the panel of experts, Quinn and Rohrbaugh (1983) then asked the surveyed $A S Q$ authors to make judgments about the similarity between every possible pairing of the 17 criteria. The resulting groupings of individual effectiveness elements, derived using multidimensional scaling, have since been followed up and extended in a prize-winning study by Doty et al. (1993). In it the authors-rather than seek to combine all the elements of effectiveness, as might have occurred during the excitement stage-tested the effects of different organizational forms on various measures of effectiveness. Their approach is thus more in accordance with the prescriptions of a validity policing framework.

In addition to the competing-values theoretical model, another approach used to categorize the elements of organizational effectiveness drew on a political perspective; namely, by taking the points of view of an organization's various constituencies concerning which criteria should define effectiveness (Connolly et al. 1980). This "multiple constituency" approach asks "whose perspective should dominate in the use of these criteria. Is it the perspective of the owners, employees, managers, or public at large that determines the type of criteria and the level of effectiveness desired?" (Goodman and Pennings 1977a, p. 5). The assumption of this political approach is 
that different stakeholders will emphasize completely different criteria for assessing organizational effectiveness (Evan 1993, Scott 1977 and 1992) on the basis of their own utility functions. Unlike the competing-values typology, though — which emphasizes that all the values are important to organizations and differ only in relative emphasis - the multiple constituency approach focuses on whose values will prevail.

The underlying point of both typologies, though, is that organizational effectiveness is essentially a value-based concept that is not amenable to anything approximating a "right" answer. Furthermore, the values and value judgments embodied in these positions do not particularly lend themselves to empirical testing or validation. Thus, as Zammuto (1984, p. 614) concluded, "Organizational effectiveness fundamentally is a value-based concept in that the whole of the evaluation process requires the application of value judgments. ... Theoretically, there are a potentially infinite number of value perspectives about the desired state of social arrangements on which these judgments could be based. As a result, there are a potentially infinite number of effectiveness models."

\section{Construct Collapse}

Thus the attempts by Scott (1977), Quinn and Rohrbaugh (1983), and others to categorize organizational effectiveness variables could not create a coherent organizational effectiveness umbrella construct that encompassed all these divergent meanings. Because such a consensus was deemed impossible, the "validity police" position (e.g., Goodman et al. 1983) emerged to argue for a halt to or pull back on studies of this umbrella construct. Scott (1977, p. 74) also arrived at this position: "In my opinion it will be more useful at the present stage of theoretical development to formulate more limited criteria" of effectiveness, i.e., to focus on its elements. And Kahn (1977, p. 237) suggested that "organizational effectiveness might be dropped in favor of more specific organizational outcomes." Nevertheless, Kahn (1977, p. 238) noted that the majority view among researchers at that time was to retain the effectiveness construct but to try to give it "a more satisfactory definition and theoretical position." The most forceful "validity cop" was Goodman, who argued in a 1979 presentation at the Academy of Management meetings that "there should be a moratorium on all studies of organizational effectiveness, books on organizational effectiveness, and chapters on organizational effectiveness" (Goodman et al. 1983). A few years later, Goodman, with Atkin and Schoorman (1983, p. 175), again called for "a moratorium on traditional studies of $O E$ [organizational effectiveness]," accurately predicting that the "result will be studies on satisfaction, productivity, and accidents, but not on $O E$ " (emphasis in the original).

Throughout the 1980s and 1990s, since these calls for a moratorium, research on the organizational effectiveness umbrella has been in decline, and the explicit study of organizational effectiveness has dropped from the forefront of the field. To get a rough measure of this decline, we searched the ABI/INFORM database of management and business periodicals, selecting only from among articles that included references. Of these academic and quasi-academic articles, the proportion that mentioned (a variant of) organizational effectiveness in the title, descriptor, or abstract has decreased from $0.30 \%$ of articles in 1977 to $0.10 \%$ of articles in 1994-a 68\% drop (see Figure 1). ${ }^{1}$

Although the actual number of effectiveness articles published per year did not change much over the 17-year period (while the number of journals increased dramatically), change in the proportion of articles (with references) is used here because we believe it is a better measure of the relative growth or decline of a field of study. So organizational effectiveness as an explicit construct plays a much diminished role today compared with mid1970s.

\section{The Umbrella's Elements}

An important part of the calls for an end to studies of organizational effectiveness as an umbrella construct, though, was a recognition of the need to keep studying the various underlying elements of organizational effectiveness (Goodman et al. 1983, Scott 1977). In uncovering the story of whatever happened to effectiveness, then, we need to know what were all the major elements of effectiveness and how they have fared in the literature since the decline of the umbrella construct. Using the 17

\section{Figure 1 Proportion of Articles (with References) Published on Organizational Effectiveness}

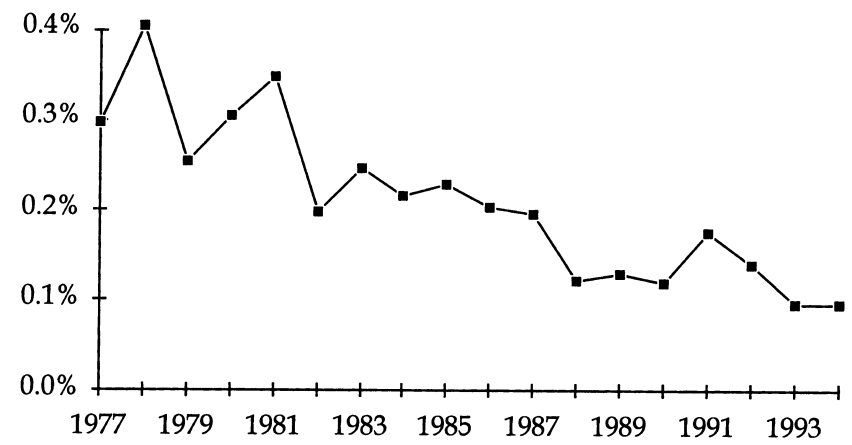

Source: ABI/INFORM Database 


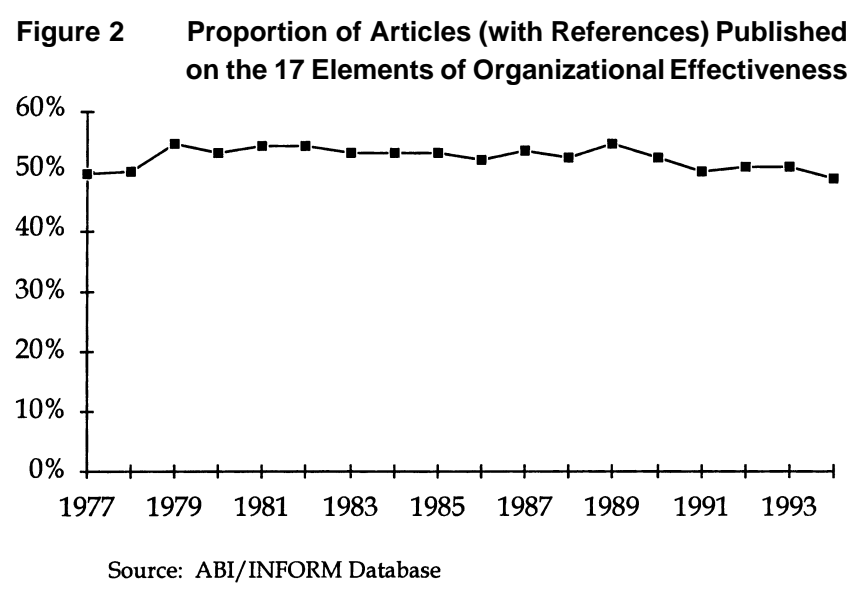

elements of effectiveness identified by Quinn and Rohrbaugh (1983), we searched the ABI/INFORM database to see whether the study of these elements has also declined over the 17-year period. The database search included all articles (with references) mentioning any of the 17 elements in the title, descriptor, or abstract (see Table 1).

As shown in Figure 2, the proportion of articles addressing elements of effectiveness has remained relatively constant, from $49.7 \%$ of articles with references in 1977 to $48.8 \%$ of such articles in 1994. Approximately half of all articles with references dealt with one or more of these elements of organizational effectiveness. The sheer size of this statistic suggests that the elements of organizational effectiveness play a large role in the study of management and organizations, although some of the search terms could have inflated the number of articles identified. So, while attempts to integrate these elements of organizational effectiveness under a single umbrella may have petered out, the study of the elements themselves has not.

\section{The Umbrella Construct Process}

Is the story of effectiveness an isolated case? Is the rise and fall of this construct idiosyncratic? We propose not. Indeed, we believe it is a prototype umbrella construct, and has followed the same life-cycle as other constructs created at this level of analysis.

We propose in Figure 3 a model for the life-cycle of umbrella constructs in general, with current examples (discussed in the next section) from organizational science.

Interestingly, this model somewhat resembles the standard four-stage model (or, S-curve) of product life-cycles: introduction, growth, maturity, and decline (Lambert 1985), and similar life-cycle models of technologies and of industries. For, as Meyer (1997) suggests, "the business of producing scholarship may [sometimes] follow
1) Productivity
2) Efficiency
3) Profit
4) Quality
5) Morale
6) Growth
7) Control
8) Conflict/Cohesion
9) Flexibility/Adaptation
10) Planning and Goal Setting
11) Information Management and Communication
12) Readiness
13) Utilization of Environment
14) Evaluations by External Entities
15) Stability
16) Value of Human Resources
17) Training and Development Emphasis

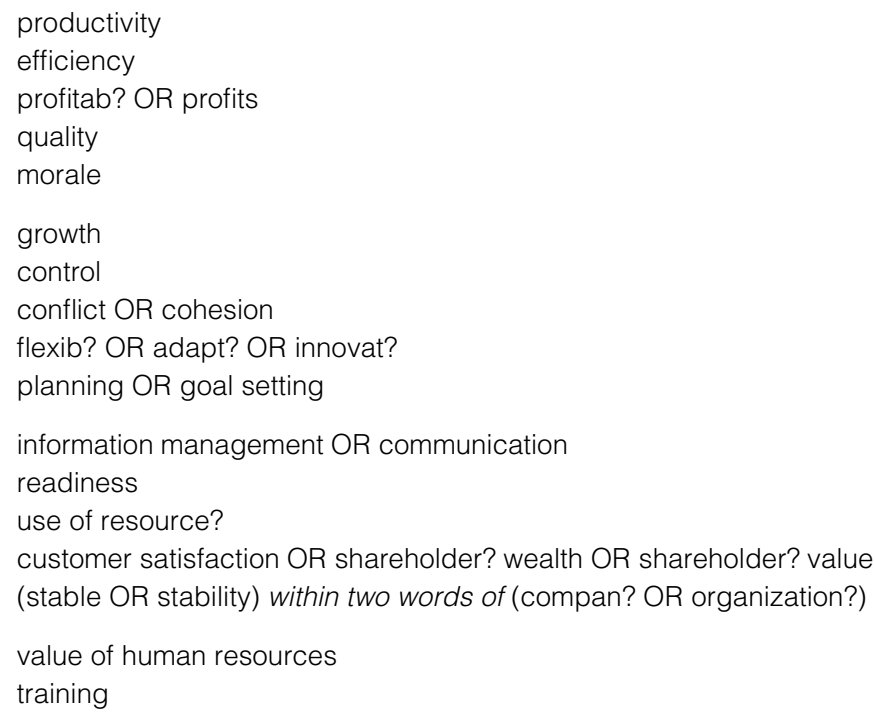

Note: A ? indicates a search for all variants of the truncated word; e.g., profitab? includes profitable and profitability. 


\section{Figure 3 Proposed Umbrella Construct Process with Current Examples}

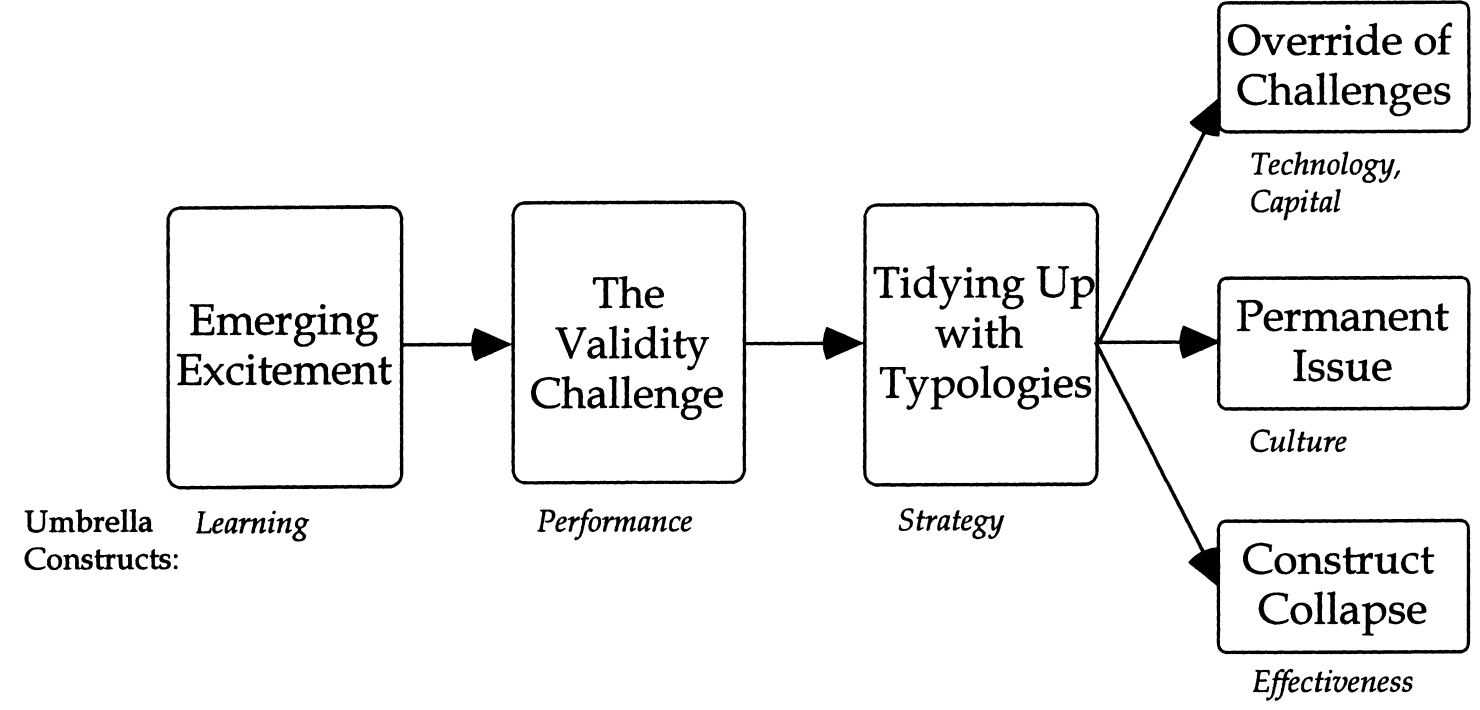

dynamics similar to the business of making silicon chips or constructing industries."

The model in Figure 3 proposes that all umbrella constructs pass through each of these stages. In the final stage, scholars either make the construct coherent (override of challenges), agree to disagree over its definition (permanent issue), or call for its demise (construct collapse). Consistent with this process model, we present below several propositions on the dynamics of umbrella constructs.

Why do umbrella constructs arise in the first place, and in what situations are they especially likely to appear? One reason for the initial appearance of umbrella constructs is cognitive. Too many unconnected concepts would make our understanding of the world difficult to follow and comprehend. Combining elements into an umbrella construct "provide[s] a way to organize a large body of what might otherwise seem to be unrelated findings" (Astley 1985, p. 501); i.e., it helps create some theoretical order, at least at first. In the case of organizational effectiveness, the 17 elements of the umbrella construct all seem as if they belonged together. This seeming coherence, though, stems from the fact that all 17 elements are normative goals for organizations; effectiveness is thus a summation of the many things organizations should strive for. Upon further analysis, though, the cognitive benefits of the umbrella construct start to fall apart.

A second reason scholars use umbrella constructs is "political." A researcher can make others take interest in and accept his or her work by paying homage to the current, institutionalized umbrella construct. Doing so makes the individual's research more legitimate, both among fellow scholars and in the eyes of funding agencies. The process that allows these connections to the umbrella constructs to occur is quite similar to the de-coupling between stated goals and actual actions that often occurs in organizations (Meyer and Rowan 1977). Finding ways to join a small piece of research to broader umbrella-like ideas is thus a kind of strategic ambiguity (Eisenberg 1984), where political consensus, not clarity, is the primary goal. In short, these linguistic ambiguities "are robust mechanisms for generating scientific communion" (Astley 1985, p. 501). Of course the political benefits of linking up to an umbrella construct are probably greatest in the earlier stages of the umbrella's life-cycle-later on, authors are often forced to trade off these benefits against the costs of having to try to respond to the ever-growing challenges from the validity police.

So even though conceptual umbrellas may come and go-with the underlying elements presumably migrating from one umbrella to another-these umbrellas are often necessary for establishing intellectual linkages among otherwise isolated researchers. Given this rationale for the appearance of umbrella constructs-that researchers are looking for linkages to the work of others-in what fields might such umbrella constructs be especially prevalent?

We argue that umbrella constructs are especially prevalent in what we call umbrella fields, fields like organizational behavior that themselves try to encompass a broad, diverse set of topics and theories. Ghorpade (1971, p. 7), for example, is hardly alone in pointing out that "there does not exist a universally accepted theoretical framework for approaching the study of organizations." 
Pfeffer (1993), too, notes that organizational science is a field that-in contrast to, say, economics or demography-lacks a unified paradigm that can be efficiently developed. And without such a unified paradigm, otherwise isolated researchers will be looking hard for ways to establish intellectual linkages, ways to try to make the field more coherent and integrated and tie their work to a rising conceptual star. Umbrella constructs are enablers to meet this goal. An umbrella field such as organizational behavior will likely contain more of these constructs because they serve as the glue that hold such diverse fields together. Hence we present the following proposition.

Proposition 1. The more a field lacks theoretical consensus, the more it will rely on umbrella constructs to tie together different research elements.

One particularly distinctive stage in the overall process shown in Figure 3 is the second stage, the validity challenge. All concepts probably have their validity challenged at some point or other, since, as the philosopher Wittgenstein (1968) noted, they are all difficult, if not impossible, to define precisely. Yet umbrella constructs face a more serious hurdle because, while most concepts_as Aristotle long ago observed (Barnes 1995) —at least have a central or focal meaning, an umbrella construct, by definition, encompasses a wide diversity of elements. As a result, it will encounter very serious problems (inevitably) when researchers try to make the construct coherent and operationalize it. Even if most researchers never define the construct and ignore one another's operationalizations of it - as Shenhav et al. (1994) claim has occurred with organizational "goodness" constructs like effectiveness, performance, and productivity-ultimately, we believe, "validity cops," like Shenhav et al. (1994) will also take notice. Thus one of the basic propositions indicated by our model can be stated as Proposition 2 .

Proposition 2. An umbrella construct that seeks to tie different research elements together will eventually have its validity seriously challenged.

In addition to the proposed life-cycle stages shown in Figure 3, another aspect of an umbrella construct's life cycle concerns the elements of the construct. When validity police finally call a halt to the indiscriminate use of an umbrella construct, the validity of its constituent elements is not necessarily also challenged. In fact, researchers in all likelihood will continue with their study of the elements because those elements are for the most part still on the same topic of interest as the umbrella. Furthermore, whatever an umbrella's elements may lack in broad appeal, they may more than make up for in coherence and validity. We therefore predict:

Proposition 3. The elements of an umbrella construct that has collapsed will outlive the construct.

Indeed, as we document in the next section, an important subset of these elements now appears in the growing literature on the newer (replacement?) umbrella construct of organizational performance. That is, not long after the demise of the organizational effectiveness construct, a kind of organizational effectiveness clone arguably arose to take its place. In this pattern, a construct that has collapsed reappears under another name. If this pattern is typical, a feedback loop is added in Figure 3 from the collapse of a construct back to the excitement stage for the new one. That is, just as validity police may prevent umbrella advocates from going too far for too long with an unwieldy and ill-defined construct, so too the umbrella advocates may ultimately prevent the validity police from shutting down the field's need to touch base with broader, albeit renamed, conceptual tents and umbrellas that try to encompass diverse elements.

Proposition 4. An umbrella construct that undergoes collapse will be reborn with a new and different name.

One interesting characteristic of the organizational effectiveness debate is that it was limited primarily to academic circles. That is, organizational effectiveness remained an umbrella construct without a large outside "constituency" of practitioners who publicly support, study, and think about the issue. Other umbrella constructs, however, have become current in both the scholarly and practitioner worlds, e.g., corporate strategy, culture, technology, capital. Yet it is primarily in the academic world that the validity police speak out most forcefully and in which one would most expect to find their admonitions heeded. As a participant/observer of this conflict between umbrella advocates and validity police in the scholarly realm (and a reviewer of this article) informed us:

\footnotetext{
One aspect of the validity challenge that played a major role in the collapse of the effectiveness construct was the editorial review process. By the late 1970s and through the 1980s, individuals submitting manuscripts on organizational effectiveness found themselves being challenged to carefully define how they were using the term by reviewers. (You can contrast this with the excitement stage where authors used the term loosely to tie their work to a conceptually rising star and generally getting away with it.) I also think this is probably the single most important reason for the rise of studies of "organizational performance." It literally became dangerous for an author to use the
} 
term effectiveness in an article (or its title) unless it was tied to some model that provided a bounded definition of the concept. As a result, authors who wanted to minimize their problems in the review process quickly learned to identify their studies as being concerned with specific components of the effectiveness construct and the umbrella construct itself fell into disfavor.

The editorial review process for scholarly journals is likely a critical mechanism used to enforce the validity police's position on an umbrella construct within the academic world.

At first glance this process might appear to lead inevitably to construct collapse within the academic literature for any umbrella construct — regardless of what might be occurring in the practitioner literature. Yet some research findings suggest otherwise. Barley et al. (1988, p. 24) note that in the case of the umbrella construct of organizational culture, "academics appear to have moved toward practitioners' point of view, while the latter appear to have been little influenced by the former." Since the practitioner world lacks the countervailing pressure of a strong validity police, those with a broad view of umbrella constructs may be able to overrule validity objections and thus allow an umbrella construct to "override the challenges" and live on, i.e., "the business community [may sponsor and] support lines of inquiry that the discipline's internal control system might not otherwise endorse" (Astley 1985, p. 509). Umbrella constructs such as technology or capital may have become taken for granted in part through just such a mechanism. Thus one might posit that, in the academic world:

PROPOSITION 5. The more an umbrella construct has a (nonacademic) constituency, the less vulnerable that umbrella construct will be to validity challenges.

Although the study of managerial fads (Abrahamson 1996) is beyond the scope of this paper, it is important to note that these trends in the practitioner world may have some influence on the rise and fall of umbrella constructs among scholars.

\section{Implications for Current Umbrella Constructs}

Within organizational behavior today, researchers are struggling to advance and define several umbrella constructs which are at different stages in our proposed lifecycle model (see Figure 3).

\section{Learning}

The construct of organizational learning, though it has been the subject of study for some time (Argote 1993), has only recently burst on the scene in a prominent way and entered "the excitement stage" (see Figure 3), e.g., appearing in 1991 and 1992 special issues of Organization Science and as the theme of the 1996 Academy of Management meetings. In fact, "Organizational learning now stands on the threshold of moving center stage in organization theory" (Miner and Mezias 1996, p. 90). That organizational learning is an umbrella construct is suggested by the comment by Fiol and Lyles (1985, p. 805 ) that "the organizational learning literature is full of multiple interpretations of the concept." Yet like organizational effectiveness researchers during that concept's excitement stage, Fiol and Lyles (1985) do not seriously challenge the validity of the overall construct but rather put forth their own definition, as do Levitt and March (1988), Huber (1991), Walsh and Ungson (1991), and Nonaka (1994).

Huber (1991), who elaborates four broad constructs (elements) of organizational learning, calls for-again, as did several researchers of organizational effectiveness during its excitement stage-more integration and synthesis of the research on organizational learning. Moreover, in true umbrella advocate fashion, Huber (1991, p. 89) urges, "It is important to challenge narrow concepts of organizational learning, or of any phenomenon early in the history of inquiry, as narrow conceptions decrease the chances of encountering useful findings or ideas." Despite this plea, however, we expect organizational learning soon to enter the stage of having its construct validity seriously challenged. Strong practitioner interest in the related notion of "the learning organization" (Garvin 1993, Senge 1990), though, may ultimately save the umbrella construct from becoming fragmented into its constituent elements by the validity police.

\section{Performance}

As noted earlier, an umbrella construct currently at the second stage - namely, the validity challenge - of our proposed model (see Figure 3) is organizational performance. This construct, which is quite similar to effectiveness - it has many of the same definitions and indicators (Shenhav et al. 1994) — adds a further twist to the organizational effectiveness story. Meyer (1994) has found organizational performance contains some of the same problems that we note as common among umbrella constructs in general. For example, Meyer and O'Shaughnessy (1993, p. 251), citing five large-scale studies from the late 1980s, concluded that "accounting measures [of performance such as] sales and profits are essentially independent of financial measures such as market value, return on equity, and change in share prices." Unlike organizational effectiveness, however, research on the umbrella construct of organizational performance has hardly disappeared from the literature; on 
the contrary, the decline of articles on effectiveness has coincided with the rise of articles on performance. In fact, according to the ABI/INFORM database, articles (with references) on organizational performance have become more common than ones on organizational effectiveness since the mid-late 1980s (see Figure 4).

Similarly, in their study of articles published in four leading academic journals, Shenhav et al. (1994) find that from 1956 to 1990, articles were initially more likely to be on effectiveness than on performance but that eventually the reverse became true. Of course the two terms have always been somewhat interchangeable; in fact, according to our analysis of the Shenhav et al. (1994) data, an annual increase in the number of articles for one construct has often coincided with a decrease for the other $(r$ $=-0.54)$. Interestingly, though, the overall trend among these four prominent journals was that performance definitively surpassed effectiveness as early as 1979-the same year Goodman began calling for a moratorium on further organizational effectiveness studies (Goodman et al. 1983).

We still expect organizational performance to continue its movement through the validity challenge stage in the footsteps of effectiveness. We note, though, that, in contrast to the organizational effectiveness saga, the number of researchers who-like Meyer (1994) and Shenhav et al. (1994) - have noted the performance construct's "umbrella-ness" and questioned its validity remains small (so far). Moreover, the organizational performance literature includes many more practitioners and is not nearly as introspective as was the organizational effectiveness literature, e.g., articles on performance have been much less likely to state a nominal (theoretical) definition of the construct than have articles on effectiveness (Shenhav et al. 1994). So whether performance, too, will fall by the wayside or narrow in scope once the validity police require better operationalizations remains to be seen.

\section{Strategy}

Strategy, too, has come to have multiple meanings and interpretations that have been tidied up with typologies. For example, Meyer (1991), after interviewing more than 35 researchers and scholars, identified two entirely different conceptions of strategy, one he called structural and the other processual. Whereas proponents of the narrower, structural perspective are perhaps most analogous to validity police, those viewing strategy as an ongoing process tend to be umbrella advocates who see many benefits to strategy's "umbrella-ness." Although strategy, broadly speaking, is in many ways a field of study, one of Meyer's (1991, p. 831) informants makes clear that strategy is nonetheless first and foremost an umbrella construct:

\footnotetext{
The whole field of strategy demonstrates the power of a nonconcept-strategy or policy. Neither strategy or policy has a meaning. In the extreme, they mean everything. For example, Mintzberg's concept of strategy is synonymous with behavioranything that happens is a strategy. Thus, strategy and policy resemble power in political science. They are catch-all concepts that denote anything and so they mean nothing and they cannot be operationalized. Yet they form the core around which a field has organized itself. There may be a profound point here about the nature of academic fields!
}

This informant has identified a key insight: even though strategy, like other umbrella ("catch-all") constructs, may lack conceptual validity, it is nonetheless an important unifier among researchers trying to organize an academic field.

So, as with organizational effectiveness, researchers

Figure 4 Proportion of Articles (with References) Published on Organizational Performance versus Organizational Effectiveness

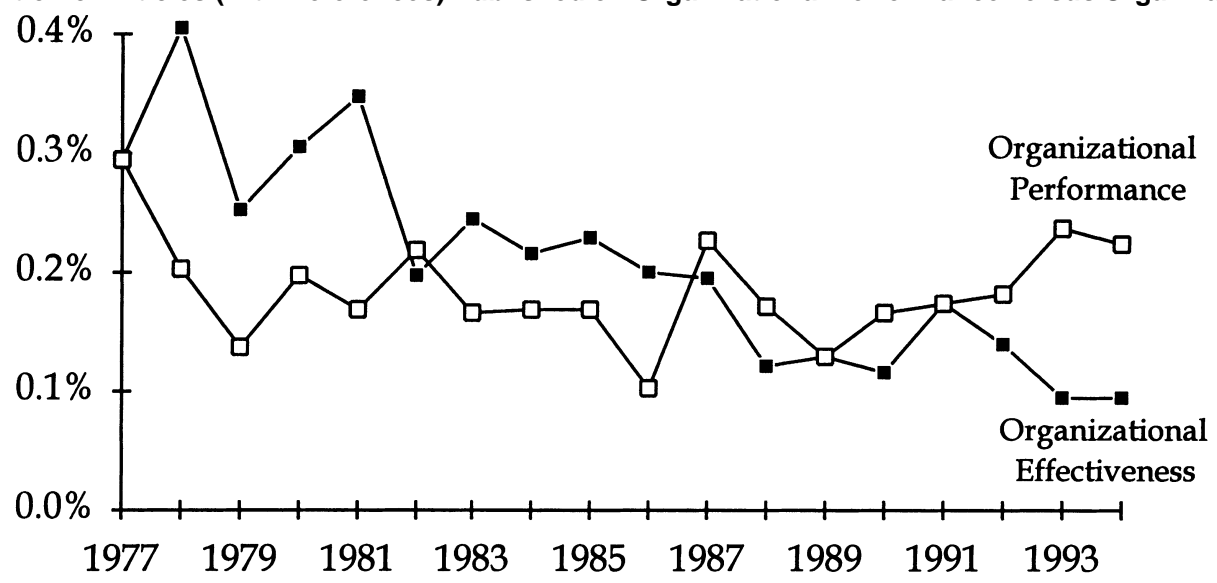


have tried to "tidy up" and categorize the various elements of the umbrella construct of strategy when the umbrella as a whole cannot be made coherent. The ultimate fate of the construct, however, remains unclear. Structuralists - the validity police of the strategy construct-may yet succeed in overriding the challenges (see Figure 3 ) to strategy's validity by shrinking the umbrella to include fewer elements-in contrast to the collapsed effectiveness umbrella, which always remained ambitious and broad. Alternatively, those with a process-based view of strategy — the umbrella advocates-may ultimately make the debate a permanent issue, creating an enduring pluralistic "dialogue between academic disciplines" (Meyer 1991, p. 831) and perspectives.

\section{Culture}

It was in "the late 1970s that the notion of organizational culture began to attract explicit and sustained interest. [It then] gathered momentum slowly until 1982, when interest in organizational culture suddenly mushroomed" (Barley et al. 1988, p. 31-32). Interestingly, as with the shift from effectiveness to performance, a similar process may also have occurred during the excitement stage of organizational culture, for "a comparison of [the] recent culture research with the organizational 'climate' literature of the 1960s and 1970s shows a curious similarity and suggests that it is becoming increasingly difficult to distinguish some of the current culture research from the earlier climate paradigm" (Denison 1996, p. 644). (And though it may not be quite fair to say that climate research has collapsed, its prominence has at least waned since its heyday.)

Ten years after this beginning of the excitement stage, Martin (1992, p. 4), in her review of the literature on organizational culture, laid out the validity challenge to the construct: "This is, however, an area of inquiry that lacks a common definition of its central concept (culture) and has no theoretical paradigm that cultural researchers share." Martin's (1992) book takes this challenge to the next stage of tidying up with typologies; in this case, identifying and describing the "three social science perspectives [integration, differentiation, and fragmentation] that have come to dominate organizational culture research" (p. 4). Martin (1992, p. 4) may also successfully move the debate over culture's construct validity to the final stage (see Figure 3); in this case, toward becoming a permanent issue, where researchers agree to disagree over specifics and even basic definitions. "Thus," she writes, one "goal of this book is to suggest why this [lack of theoretical agreement] is an understandable and perhaps even a desirable state of affairs." Smircich (1995, p. 233; see also Calas and Smircich 1987, Jelenik et al. 1983) has also taken the position that researchers should stop arguing about what organizational culture really is "and focus instead on analyses of the processes of representation."

\section{Conclusion}

We have argued against the orthodox view that organizational behavior is a field of pure progress; i.e., that the field's "knowledge [only] grows linearly as new data are added to the existing stock of research findings" (Astley 1985, p. 497). At the same time, we do not go so far as to argue that theoretical precision is unattainable or that "the field's development is characterized ... by a growing divergence in research perspectives" (Astley 1985, p. 497). Rather, we have tried to show that there are elements of a cyclical process within the field, where different types of perspectives are emphasized at different times. Furthermore, though each of us may have his or her own leanings, the field as a whole probably needs both broad (umbrella) and narrow (policing) perspectives, for this dialectic can be useful for understanding and explaining the underlying issues of organizational life. This struggle thus enables the field as a whole to balance its competing needs to be both scientific and relevant.

Our inquiry into whatever became of organizational effectiveness has led to distinctions between umbrella constructs and their constituent elements. In the case of umbrella constructs, an unwieldy and overly broad umbrella is conceptually analogous to Type II errors; they may include too many elements. Note that other theories or constructs (e.g., population ecology, neo-classical economics) may be more analogous to Type I errors if they exclude too many interesting problems. This tension between rigor and relevance is not easily solved in the case of umbrella constructs. In fact, researchers devoted to either pole of the debate may never agree. This tension, after all, goes at least as far back as the 19th century, when debates raged in the field of taxonomy between "lumpers," who advocated a few large categories, and "splitters," who wanted many categories based on small differences (Morowitz 1979). Yet, in organizational behavior today, the dynamics that arise from these debates between umbrella advocates (lumpers) and validity police (splitters) may help keep the overall research system in a kind of equilibrium, where neither extreme can achieve total victory over the other.

Although this paper's focus has been on the life cycle of umbrella constructs, our proposed model may also have some relevance to fields such as strategy or institutional theory. In fact, in some ways, organizational behavior itself is the ultimate umbrella because it includes 
all sorts of disparate elements that may or may not hang together coherently; it is, in other words, an umbrella field. This situation, however, can be seen as either good or bad. For umbrella advocates, broad global concepts (or fields) are interesting and to be celebrated; for validity police, they are sloppy and should be eliminated. This tension, we have argued, is a healthy one which enables a field of researchers to strike a balance between relevance and integration, on the one hand, and scientific rigor and focus, on the other. Moreover, it is a tension which creates a predictable life cycle for umbrella constructs and possibly, for umbrella fields and theories as well. Pfeffer's (1993) description, quoted at the beginning of this paper, of the need for "balance" fits nicely with the dynamic, or dialectic, presented here. Interestingly, though, Pfeffer also occasionally takes on the role of "validity cop" for the field as a whole, arguing that "the domain of organization theory is coming to resemble more of a weed patch than a well-tended garden" (Pfeffer 1982, p. 1; see also Pfeffer 1993).

In relation to theory building, Dubin's (1978, p. 66) conception of "summative units" provides an interesting lesson for umbrella constructs. A summative unit is "a global unit that stands for an entire complex thing. Such global units are common in the behavioral sciences." Summative units have the strength that they can mean a great deal; at the same time, they are ill-defined or unspecified (see also Kimberly 1976). As an element of theory, they do not provide enough guidance to render clear research approaches. As a tool for empirical research, they are insufficiently specific to render clear conclusions. As with Dubin's "summative units," when autonomous umbrella constructs are imported into quasitheoretical examination, their breakdown is often only a matter of time. Umbrella constructs thus differ from conventional theoretical constructs created within a theory, defined by the "primitives" of that theory and proposed in terms of their relationships to other factors.

While philosophers of science have remarked in the past on the limited utility of umbrella constructs, suggesting they not be used for theoretical research at all, we have shown that such attention does occur, both in the case of effectiveness and the more recent grand constructs of learning, performance, strategy, and culture, all capturing the attention of many and generating a great deal of energy and excitement. We have also offered a model which describes and analyzes the fate of effectiveness and other umbrella constructs, both to increase our understanding of this phenomenon and so that scholars can know what to expect.
In summary, the dialectic between umbrella advocates and validity police, as played out in the experience with organizational effectiveness and other umbrella constructs, teaches us that when a scholarly idea becomes dangerously close to meaning all things to all people, that idea's validity cannot be maintained indefinitely, at least not under the same name.

\section{Acknowledgment}

The authors wish to thank Mark Jacobs, Martin Kilduff, Alan Meyer, Jeff Pfeffer, Ira Singer, Marc Ventresca, Joseph Walther, and several anonymous Organization Science reviewers for very interesting and helpful ideas, comments, and suggestions.

\section{Endnotes}

${ }^{1}$ Although it may seem that only a small percentage of articles ever dealt with organizational effectiveness during this time frame, we suspect that no single theoretical idea dominates the articles (with references) in the ABI/INFORM database. To confirm this explanation, we conducted similar searches for (variants of) organization/population ecology (annual percentages ranged between $0 \%$ and $0.05 \%$ of all articles with references), institutionalism (between $0 \%$ and $0.10 \%$ ), transaction costs (between $0.30 \%$ and $0.74 \%$ ), and organizational culture (between $0 \%$ and $1.30 \%$ ).

\section{References}

Abrahamson, E. 1999. Management fashion lifecycles, triggers, and collective learning processes. Admin. Sci. Quart. 44.

- 1996. Management fashion. Acad. Management Rev. 21254 285.

Argote, L. 1993. Group and organizational learning curves: individual, system and environmental components. British J. Soc. Psych. 32 31-51.

Astley, W. G. 1985. Administrative science as socially constructed truth. Admin. Sci. Quart. 30 497-513.

Barley, S. R., G. W. Meyer, D. C. Gash. 1988. Cultures of culture: academics, practitioners and the pragmatics of normative control. Admin. Sci. Quart. 33 24-60.

Barnes, J. 1995. Metaphysics. In The Cambridge Companion to Aristotle, J. Barnes (ed.), Cambridge University Press, Cambridge.

Campbell, J. P. 1977. On the nature of organizational effectiveness. New Perspectives on Organizational Effectiveness. P.S. Goodman, J. M. Pennings, eds. Jossey-Bass, San Francisco.

, D. E. Bownas, M. G. Peterson, M. D. Dunnette. 1974. The Measurement of Organizational Effectiveness: A Review of Relevant Research and Opinion. Navy Personnel Research and Development Center, San Diego.

Cameron, K. S., D. A. Whetten. 1983. Organizational effectiveness: one model or several? Organizational Effectiveness: A Comparison of Multiple Models. K. S. Cameron, D. A. Whetten, eds. Academic Press, New York.

1978. Measuring organizational effectiveness in institutions of higher education. Admin. Sci. Quart. 23 604-632.

Connolly, T., E. J. Conlon, S. J. Deutsch. 1980. Organizational effectiveness: a multiple constituency approach. Acad. Management Rev. 5 211-217. 
Cook, T. D., D. T. Campbell. 1979. Quasi-Experimentation: Design \& Analysis Issues for Field Settings. Houghton Mifflin, Boston, MA.

Denison, D. R. 1996. What is the difference between organizational culture and organizational climate? A native's point of view on a decade of paradigm wars. Acad. Management Rev. 21 619-654.

Doty, D. H., W. Glick, G. Huber. 1993. Fit, equifinality, and organizational effectiveness: a test of two configurational theories. Acad. Management J. 36 1196-1250.

Dubin, R. 1978. Theory Building (revised edition). The Free Press, New York.

Eisenberg, E. M. 1984. Ambiguity as strategy in organizational communication. Communication Monographs 51 227-242.

Evan, W. M. 1993. Organization Theory: Research and Design. Macmillan Publishing, New York.

Fiol, C. M., M. A. Lyles. 1985. Organizational learning. Acad. Management Rev. 10 803-813.

Garvin, D. A. 1993. Building a learning organization. Harvard Bus. Rev. 71(4) 78-91.

Ghorpade, J. (Ed.). 1971. Assessment of Organizational Effectiveness: Issues/Analysis/Readings. Goodyear Publishing, Pacific Palisades, CA.

Goodman, P. S., R. S. Atkin, F. D. Schoorman. 1983. On the demise of organizational effectiveness studies. Organizational Effectiveness: A Comparison of Multiple Models. K. S. Cameron, D. A. Whetten, eds. Academic Press, New York.

_ J. M. Pennings. 1977a. Perspectives and issues: an introduction. In New Perspectives on Organizational Effectiveness. JosseyBass, San Francisco.

— 1977b. Toward a workable framework. In New Perspectives on Organizational Effectiveness. Jossey-Bass, San Francisco.

Gouldner, A. W. 1959. Organizational analysis. Sociology Today. R. K. Merton, L. Broom, L. S. Cottrell, Jr., eds. Basic Books, New York.

Hannan, M. T., J. Freeman. 1977. Obstacles to comparative studies. New Perspectives on Organizational Effectiveness. P.S. Goodman, J. M. Pennings, eds. Jossey-Bass, San Francisco.

Huber, G. P. 1991. Organizational learning: the contributing processes and the literatures. Organ. Sci. 2 88-115.

Lambert, D. M. 1985. The Product Abandonment Decision. National Association of Accountants, Montvale, NJ.

Jelenik, M., L. Smircich, P. Hirsch. 1983. Introduction: a code of many colors. Admin. Sci. Quart. 28 331-338.

Kahn, R. L. 1977. Organizational effectiveness: an overview. New Perspectives on Organizational Effectiveness. P. S. Goodman and J. M. Pennings, eds. Jossey-Bass, San Francisco.

Kanter, R. M., D. Brinkerhoff. 1981. Organizational performance: recent developments in measurement. Ann. Rev. Sociology 7321 349.

Katz, D., R. L. Kahn. 1966. The Social Psychology of Organizations. Wiley, New York.

. 1978. The Social Psychology of Organizations second edition. Wiley, New York.
Kimberly, J. R. 1976. Organizational size and the structuralist perspective: a review, critique, and proposal. Admin. Sci. Quart. 21 571-597.

Levin, D. Z. 1988. Measuring a gerrymander. Michigan J. Political Sci. 9 63-68.

Levitt, B., J. G. March. 1988. Organizational learning. Ann. Rev. Sociology 14 319-340.

March, J. G. 1996. Continuity and change in theories of organizational action. Admin. Sci. Quart. 41 278-287.

Martin, J. 1992. Cultures in Organizations: Three Perspectives. Oxford University Press, New York.

Meyer, A. D. 1991. What is strategy's distinctive competence? J. Management 17 821-833.

- 1997. Personal communication. University of Oregon, Graduate School of Management.

Meyer, J. W., B. Rowan. 1977. Institutionalized organizations: formal structure as myth and ceremony. Amer. J. Sociology 83 340-363.

Meyer, M. W. 1994. Measuring performance in economic organizations. In The Handbook of Economic Sociology. N. J. Smelser, R. Swedberg, eds. Princeton University Press, Princeton, NJ.

— K. C. O'Shaughnessy. 1993. Organizational design and the performance paradox. Explorations in Economic Sociology. R. Swedberg, ed. Sage, New York.

Miles, R. H. 1980. Macro Organizational Behavior. Goodyear, Santa Monica.

Miner, A. S., S. J. Mezias. 1996. Ugly duckling no more: pasts and futures of organizational learning research. Organ. Sci. 7 88-99.

Morowitz, H. 1979. The Wine of Life and Other Essays on Societies, Energy \& Living Things. St. Martin's Press, New York.

Mullins, N. 1973. Theories and Theory Groups in Contemporary American Sociology. Harper \& Row, New York.

Nonaka, I. 1994. A dynamic theory of organizational knowledge creation. Organ. Sci. 5 14-37.

Pfeffer, J. 1982. Organizations and Organization Theory. Pitman, Marshfield, MA.

1993. Barriers to the advance of organizational science: paradigm development as a dependent variable. Acad. Management Rev. 18 599-620.

Price, J. L. 1968. Organizational Effectiveness: An Inventory of Propositions. Richard D. Irwin, Inc., Homewood, IL.

Quinn, R. E., J. Rohrbaugh. 1983. A spatial model of effectiveness criteria: towards a competing values approach to organizational analysis. Management Sci. 29 363-377.

Scott, W. R. 1977. Effectiveness of organizational effectiveness studies. In New Perspectives on Organizational Effectiveness. P. S. Goodman, J. M. Pennings, eds. Jossey-Bass, San Francisco.

- 1992. Organizations: Rational, Natural, and Open Systems. (third edition) Prentice Hall, Englewood Cliffs, NJ.

Senge, P. M. 1990. The Fifth Discipline: The Art and Practice of the Learning Organization. Currency Doubleday, New York.

Shenhav, Y., W. Shrum, S. Alon. 1994. 'Goodness' concepts in the study of organizations: a longitudinal survey of four leading journals. Organ. Studies 15 753-776.

Smircich, L. 1995. Writing organizational tales: reflections on three books on organizational culture. Organ. Sci. 6 232-237. 
PAUL M. HIRSCH AND DANIEL Z. LEVIN Umbrella Advocates Versus Validity Police: A Life-Cycle Model

Thompson, J. D. 1967. Organizations in Action. McGraw Hill, New York.

Walsh, J. P., G. R. Ungson. 1991. Organizational memory. Acad. Management Rev. 16 57-91.

Wittgenstein, L. 1968. Philosophical Investigations (3d ed., transl., G. E. M. Anscombe). Basil Blackwell, Oxford.
Yuchtman, E., S. E. Seashore. 1967. A system resource approach to organizational effectiveness. Amer. Soc. Rev. 32 891-903.

Zammuto, R. 1984. A comparison of multiple constituency models of organizational effectiveness. Acad. Management Rev. 9 606-616. Zuckerman, H. 1988. The sociology of science. Handbook of Sociology. N. J. Smelser, ed. Sage, Newbury Park, CA.

Accepted by Alan D. Meyer; received March 1998. This paper has been with the authors for two revisions. 